\title{
IMPLEMENTASI ALGORITMA YOU ONLY LOOK ONCE (YOLO) UNTUK DETEKSI KORBAN BENCANA ALAM
}

\author{
Moechammad Sarosa ${ }^{1}$, Nailul Muna*² \\ 1,2 Jurusan Teknik Elektro, Politeknik Negeri Malang \\ Email: ${ }^{1}$ msarosa@polinema.ac.id, ${ }^{2}$ nailulmuna@polinema.ac.id \\ *Penulis Korespondensi
}

(Naskah masuk: 25 November 2020, diterima untuk diterbitkan: 21 Juli 2021)

\begin{abstract}
Abstrak
Bencana alam merupakan suatu peristiwa yang dapat menyebabkan kerusakan dan menciptakan kekacuan. Bangunan yang runtuh dapat menyebabkan cidera dan kematian pada korban. Lokasi dan waktu kejadian bencana alam yang tidak dapat diprediksi oleh manusia berpotensi memakan korban yang tidak sedikit. Oleh karena itu, untuk mengurangi korban yang banyak, setelah kejadian bencana alam, pertama yang harus dilakukan yaitu menemukan dan menyelamatkan korban yang terjebak. Penanganan evakuasi yang cepat harus dilakukan tim SAR untuk membantu korban. Namun pada kenyataannya, tim SAR mengalami kendala selama proses evakuasi korban. Mulai dari sulitnya medan yang dijangkau hingga terbatasnya peralatan yang dibutuhkan. Pada penelitian ini sistem diimplementasikan untuk deteksi korban bencana alam yang bertujuan untuk membantu mengembangkan peralatan tim SAR untuk menemukan korban bencana alam yang berbasis pengolahan citra. Algoritma yang digunakan untuk mendeteksi ada atau tidaknya korban pada gambar adalah You Only Look Once (YOLO). Terdapat dua macam algoritma YOLO yang diimplementasikan pada sistem yaitu YOLOv3 dan YOLOv3 Tiny. Dari hasil pengujian yang telah dilakukan didapatkan F1 Score mencapai 95.3\% saat menggunakan YOLOv3 dengan menggunakan 100 data latih dan 100 data uji.
\end{abstract}

Kata kunci: Bencana Alam, Convolutional Neural Network (CNN), Deteksi Korban, Deteksi Objek,You Only Look Once (YOLO)

\section{IMPLEMENTATION OF YOU ONLY LOOK ONCE (YOLO) ALGORITHM FOR NATURAL DISASTER VICTIM DETECTION}

\begin{abstract}
Natural disasters are events that can cause damage and create havoc. Buildings that collapse and can cause injury and death to victims. Humans can not predict the location and timing of natural disasters. After the natural disaster, the first thing to do is find and save trapped victims. The handling of rapid evacuation must be done by the SAR team to help victims to reduce the amount of loss due to natural disasters. But in reality, the process of evacuating victims of natural disasters is still a lot of obstacles experienced by the SAR team. It was starting from the difficulty of the terrain that is reached to the limited equipment needed. In this study, a natural disaster victim detection system was designed using image processing that aims to help find victims in difficult or vulnerable locations when directly reached by humans. In this study, a detection system for victims of natural disasters was implemented which aims to help develop equipment for the SAR team to find victims of natural disasters based on image processing. The algorithm used is You Only Look Once (YOLO). In this study, two types of YOLO algorithms were compared, namely YOLOv3 and YOLOv3 Tiny. From the test results that have been obtained, the F1 Score reaches $95.3 \%$ when using YOLOv3 with 100 training data and 100 test data.
\end{abstract}

Keywords: Convolutional Neural Network, Natural Disasters, Object Detection, Victim Detection, You Only Look Once (YOLO)

\section{PENDAHULUAN}

Indonesia merupakan negara yang mempunyai struktur alam yang terdiri dari pertemuan lempenglempeng tektonik yaitu Eurasia, Indo-Australia dan Pasifik. Hal tersebut menjadikan kawasan Indonesia memiliki kondisi geologi yang sangat kompleks. Kondisi ini mengakibatkan banyak daerah-daerah di Indonesia yang sangat rawan terhadap bencana alam seperti gempa bumi, tsunami, serta letusan gunung berapi. Daerah-daerah rawan bencana di Indonesia 
hampir semuanya berada pada daerah yang tingkat penduduknya sangat tinggi. Selain bencana alam yang diakibatkan oleh faktor geologi, Indonesia juga sering mengalami bencana yang dipicu oleh kerusakan alam akibat perbuatan manusia seperti banjir dan tanah longsor (Ramadhan \& Prihandoko, 2017). Berdasarkan data dari Badan Nasional Penanggulangan Bencana (BNPB) pada tahun 2019 tercatat terjadi bencana sebesar 1911 kejadian. Pada saat terjadinya bencana salah satu hal yang penting adalah proses evakuasi korban bencana. Namun pada kenyataannya, seringkali ada kendala dalam proses evakuasi. Saat ini proses evakuasi korban bencana masih belum ada teknologi yang tepat guna sehingga menyulitkan tim SAR dalam proses tersebut.

Salah satu cara untuk mendeteksi objek bencana yaitu dengan menerapkan pengolahan citra (Hartawan, et al., 2019). Pengolahan citra merupakan suatu bidang yang semakin berkembang dalam lingkup penelitian dimana sistem pengamatan secara real time meningkatkan kesempatan pada peneliti untuk mengembangkan penelitian baru pada berbagai macam masalah (ANGELO, 2018). Pemrosesan yang dilakukan yaitu deteksi objek yang diimplementasikan untuk mendeteksi keberadaan objek tertentu (Hartawan, et al., 2019). Deteksi objek berkaitan dengan identifikasi benda-benda yang terdapat di dunia nyata seperti orang, hewan, dan benda-benda. Algoritma pendeteksian objek menggunakan berbagai aplikasi pemrosesan gambar untuk mengekstraksi bagian objek yang diinginkan (Raghunandan, et al., 2018). Deteksi objek dapat diimplementasikan untuk mendeteksi korban bencana alam seperti pola tubuh manusia (Hartawan, et al., 2019). Salah satu algoritma yang diimplementasikan untuk deteksi objek yang dapat memberikan hasil yang bagus yaitu You Only Look Once (YOLO) (COROVIC, et al., 2018).

Algoritma You Only Look Once (YOLO) adalah merupakan suatu algoritma yang mendeteksi objek dengan membagi citra menjadi beberapa grid. Feature map dari keluaran YOLO menghasilkan bbox, skor objektif, dan skor kelas (Jiwoong, et al., 2019). YOLO adalah salah satu metode deteksi objek tercepat dengan kinerja yang baik dan akurasi tinggi (Fang, et al., 2020).

Pada penelitian sebelumnya, YOLO telah diimplementasikan untuk deteksi kepadatan lalu lintas. Jenis YOLO yang digunakan yaitu YOLOv3. Dari penelitian tersebut telah didapatkan hasil $F 1$ score sebesar 59\% (COROVIC, et al., 2018). YOLOv3-Tiny juga telah diimplementasikan untuk deteksi goosegrass atau gulma. Dari penelitian tersebut telah didapatkan F1 score mencapai $85 \%$ (Sharpe, et al., 2020).

Pada penelitian ini, dengan menggunakan metode YOLO, akan dirancang sistem pendeteksi korban bencana alam berbasis pengolahan citra dengan mengimplementasikan YOLOv3 dan
YOLOv3-Tiny. Perbedaan yang mendasar pada penelitian ini dari penelitian-penelitian terkait YOLO yaitu pada objek deteksi.

\section{BAHAN DAN METODE PENELITIAN}

\subsection{You Only Look Once (YOLO)}

YOLO merupakan suatu metode pengenalan objek yang berbasis pada Convolutional Neural Network (CNN) (Jeong, et al., 2018). Ilustrasi dari YOLO ditampilkan pada Gambar 1.

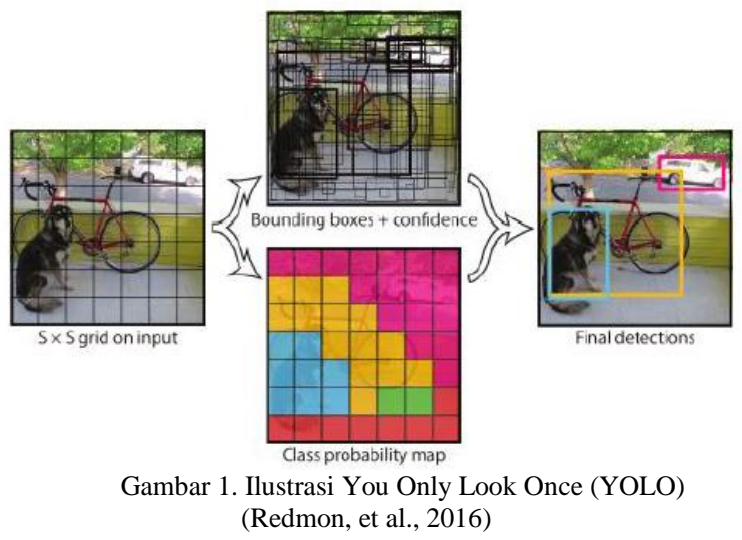

Berdasarkan Gambar 1, terdapat tiga tahapan YOLO untuk mendeteksi suatu objek. Tahapantahapan tersebut diantaranya (Asshiddiqie, et al., 2020):

1. Membagi citra menjadi grid dengan ukuran s x s untuk deteksi objek. Bounding box akan memprediksi masing-masing grid dan nilai confidence. Nilai confidence yaitu nilai dari keyakinan bounding box berisi objek sesuai perencanaan dan akurasi prediksi. Persamaa nilai confidence dapat dinyatakan pada Persamaan (1).

conf $($ class $)=\operatorname{Pr}($ Class $) \times 10 U_{\text {Pred }}^{\text {Truth }}$

$\operatorname{Pr}$ (Class) merupakan objek yang mungkin muncul dalam suatu region dan $10 U_{\text {Pred }}^{\text {Truth }}$ merupakan Intersection Of Union atau rasio tumpang tindih antara kotak prediksi dan kotak ground truth. Nilai IOU semakin besar, maka tingkat akurasi deteksi objek semakin tinggi. Persamaan IOU dapat ditampilkan pada Persamaan (2).

$10 U_{\text {Pred }}^{\text {Truth }}=\frac{\text { Area of Overlap }}{\text { Area of Union }}$

2. Setiap bounding box terdapat lima variable yaitu $\mathrm{x}, \mathrm{y}, \mathrm{w}, \mathrm{h}$, dan c. $\mathrm{x}$ dan $\mathrm{y}$ merupakan nilai koordinat dari titik tengah bounding box objek yang terdeteksi. w dan $\mathrm{h}$ merupakan nilai ukuran lebar dan tinggi. c merupakan confidence dari bounding box. 
3. Masing-masing grid memprediksi nilai probabilitas kelas apabila terdapat objek didalamnya. Nilai probabilitas kelas dan nilai confidence dari bounding box dikalikan sehigga menghasilkan nilai confidence pada setiap bounding box masing-masing kelas dengan spesifik, seperti yang ditampilkan pada Persamaan (3).

\section{$\operatorname{Pr}$ \\ (Class $\mid$ Object $) \times \operatorname{Pr}($ Object $) \times 1 O U_{\text {Pred }}^{\text {Truth }}=$ $\operatorname{Pr}\left(\right.$ Class $\left._{i}\right) \times$ IOU Pred $_{\text {Proth }}^{\text {Troj }}$}

Tahapan deteksi objek menggunakan algoritma YOLO, ditampikan pada diagram alir Gambar 2.

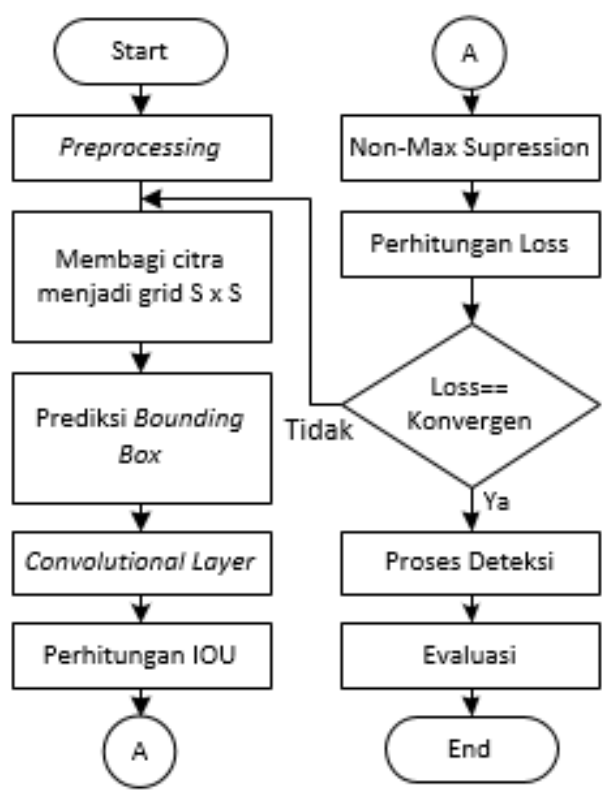

Gambar 2. Tahapan Metoe YOLO (ASSHIDDIQIE, et al., 2020)

Terdapat dua perkembangan YOLO yang diimplementasikan pada penelitian ini yaitu YOLOv3 dan YOLO-Tiny.

\subsubsection{YOLOv3}

YOLOv3 merupakan model deteksi objek yang diusulkan oleh Redmon $\mathbf{J}$ dengan mengimplementasikan deep learning dan membangun hubungan langsung antara input gambar asli dengan output, serta memiliki kecepatan dan presisi yang tinggi. Algorima ini menggunakan Darknet-53 sebagai backbone untuk mengekstrasi fitur (Rentao, et al., 2019). Arsitektur YOLOv3 menggunakan convolutional layer $1 \times 1$ dan convolutional layer $3 \times 3$ untuk mengekstraksi fitur (ADARSH, et al., 2020). Struktur jaringan YOLOv3 ditampikan pada Gambar 3.

\subsubsection{YOLOV3-Tiny}

YOLOv3-Tiny adalah versi sederhana dari YOLOv3 (Zhang, et al., 2019) dengan mengurangi depth dari convolutional layer. Sehingga kecepatan meningkat dari versi YOLO sebelumnya, tetapi akurasi deteksi semakin berkurang (ADARSH, et al., 2020). Backbone jaringan YOLOv3-Tiny yaitu terdiri dari convolutional layer dan pooling layer (Rentao, et al., 2019). Metode ini dapat meningkatkan informasi fitur objek yang terdapat pada gambar (Yang, et al., 2019). Struktur jaringan YOLOv3-Tiny ditampilkan pada Gambar 4.

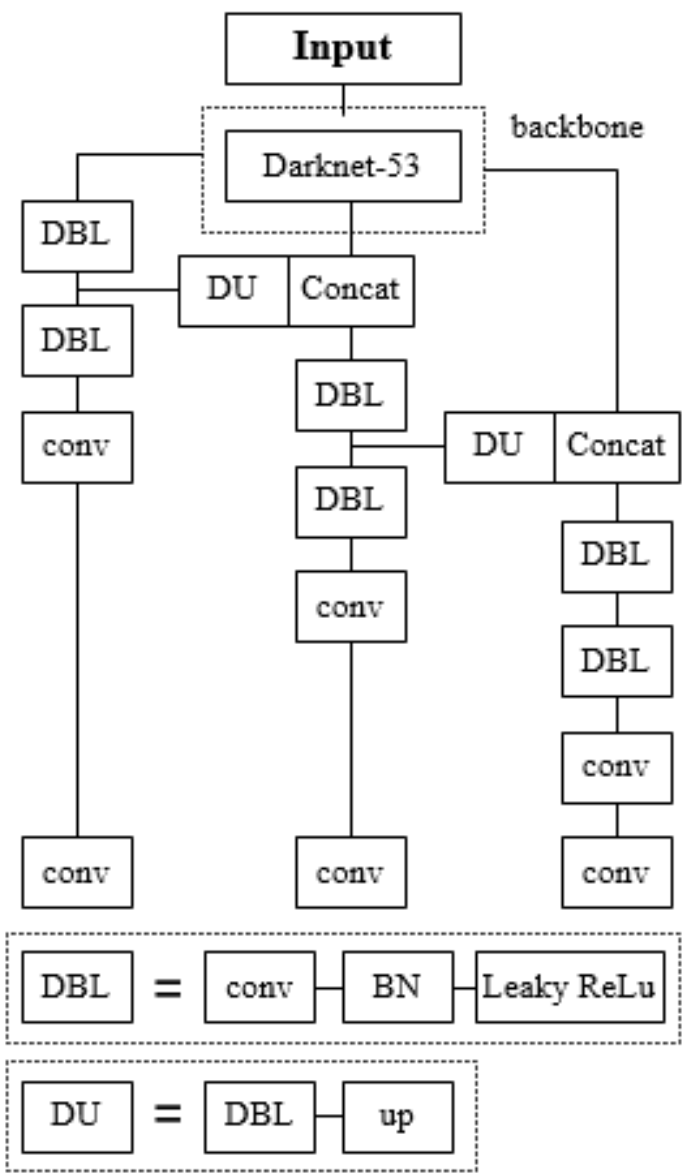

Gambar 3. Struktur Jaringan YOLOv3 (Rentao, et al., 2019)

\subsection{Dataset}

Dataset yang digunakan sebanyak 200 gambar yang terdiri dari 100 gambar untuk data training dan 100 gambar untuk data testing. Berikut contoh dataset yang digunakan pada penelitian ini ditampilkan pada Gambar 5.

Setelah data terkumpul, dilakukan anotasi data pada masing-masing gambar. Anotasi data merupakan suatu proses pemberian label pada gambar. Anotasi data dilakukan dengan cara melabeli sampah yang terdapat pada gambar. Pelabelan dilakukan dengan cara tagging secara manual pada semua gambar, baik pada data latih maupun data uji. Anotasi yang dihasilkan dari proses ini berupa bounding box berbentuk bidang persegi empat dengan keempat sisi berada tepat di sekitar luar objek korban bencana pada gambar (Zeng, et al., 2019). 


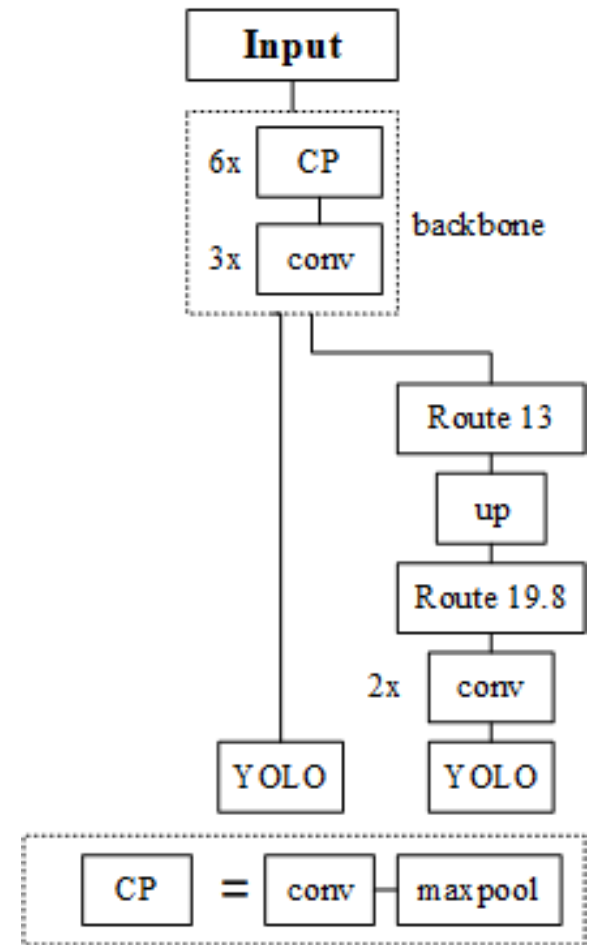

Gambar 4. Struktur Jaringan YOLOv3-Tiny (Rentao, et al., 2019)

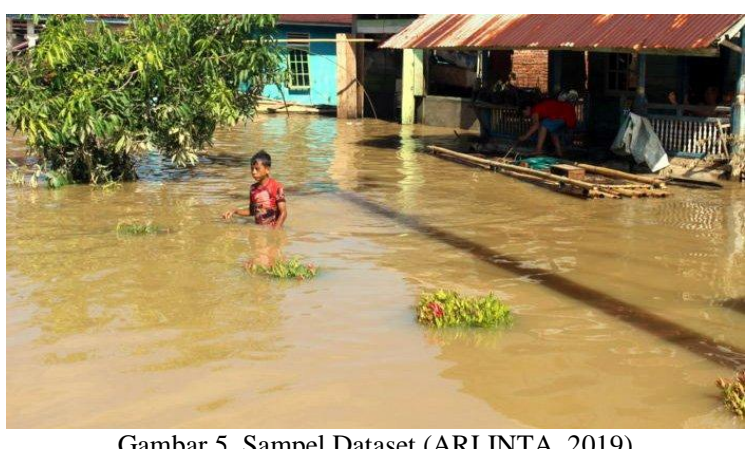

Informasi yang diperoleh dari hasil pelabelan berupa koordinat pojok kiri atas bounding box beserta dimensi panjang dan lebar, serta nama kelas objek berkas gambar yang berkaitan. Berkas disimpan sebagai berkas berekstensi .txt. Proses Training data menggunakan algoritma YOLOv3 dan YOLOv3-Tiny masing-masing dilakukan sampai step 1000, 2000, dan 3000 .

\subsection{Implementasi Sistem}

Pada penelitian ini, sistem diimplementasikan pada platform perangkat lunak visual studio 2019, CUDA 10.0, cuDNN 7.0, OpenCV 3.3 dan GPU Nvidia GeForce 940mx. Sistem Operasi yang digunakan yaitu Windows10.

\section{HASIL DAN PEMBAHASAN}

Pada sub bab ini akan dipaparkan hasil percobaan dan hasil evaluasi sistem. Hasil akan diimplementasikan pada sistem deteksi deteksi korban becana alam. Berikut hasil deteksi korban bencana alam ditampilkan pada Gambar 6 .
Berdasarkan hasil data deteksi korban bencana seperti pada Gambar 6, dapat diperoleh data yang dibagi menjadi tiga kelompok data yaitu True Positive (TP), False Positive (FP), dan False Negative (FN). TP yaitu bounding box pada kelas positif dan menghasilkan deteksi yang benar atau ketika sistem dapat mendeteksi dan melokaliasi objek dengan benar. FP yaitu bounding box pada kelas positif dan menghasilkan deteksi yang salah atau ketika objek dapat mendeteksi objek namun pada objek yang salah. FN yaitu bounding box pada kelas negatif dan menghasilkan deteksi yang salah atau ketika sistem sama sekali tidak dapat mengenali objek pada gambar yang telah diinputkan (Prasetyo, et al., 2020).

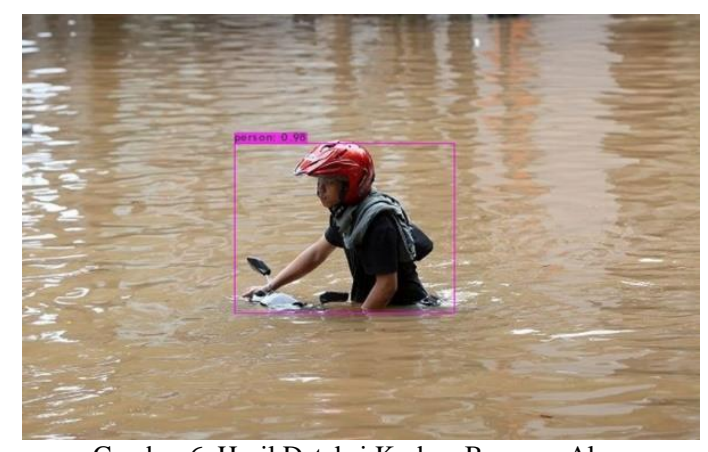

Gambar 6. Hasil Deteksi Korban Bencana Alam

\begin{tabular}{ccccc}
\multicolumn{5}{c}{ Tabel 1. Hasil Eksperimen } \\
\hline Algoritma & Step & TP & FP & FN \\
\hline YOLOv3 & 1000 & 50 & 32 & 18 \\
& 2000 & 75 & 10 & 15 \\
YOLOv3- Tiny & 3000 & 91 & 7 & 2 \\
& 1000 & 45 & 32 & 23 \\
& 2000 & 73 & 14 & 13 \\
& 3000 & 89 & 9 & 2 \\
\hline
\end{tabular}

Berdasarkan Tabel 1, Nilai TP, FP, dan FN terbaik dihasilkan oleh algoritma YOLOv3 dimana nilai TP tertinggi yaitu ketika step mencapai 3000 dengan nilai sebesar 91. Nilai FP dan FN terendah ketika jumlah step juga mencapai 3000 dimana nilai masing-masing sebesar 7 dan 2. Semakin banyak jumlah step maka nilai TP semakin tinggi, serta nilai FP dan FN semakin rendah.

Berdasarkan nilai TP, FP,dan FN pada Tabel 1, dapat diperoleh nilai Akurasi, Precision, dan Recall yang ditampilkan pada Persamaan (1), (2), dan (3).

$$
\begin{gathered}
\text { Precision }=\frac{\mathrm{TP}}{\mathrm{TP}+\mathrm{FP}} \\
\text { Recall }=\frac{\mathrm{TP}}{\mathrm{TP}+\mathrm{FN}} \\
\text { F1 Score }=\frac{2 \times \text { Precission } \times \text { Recall }}{\text { Precission }+ \text { Recall }}
\end{gathered}
$$

Berdasarkan persamaan (4), (5), dan (6) dapat diperoleh hasil evaluasi dari percobaan yang telah dilakukan yang ditampilkan pada Tabel 2. 
Tabel 2. Hasil Evaluasi Sistem

\begin{tabular}{ccccc}
\multicolumn{5}{c}{ Tabel 2. Hasil Evaluasi Sistem } \\
\hline Algoritma & Step & Precision & Recall & F1 Score \\
\hline YOLOv3 & 1000 & $60.9 \%$ & $73.5 \%$ & $66,6 \%$ \\
& 2000 & $88,2 \%$ & $83.3 \%$ & $85.7 \%$ \\
YOLOv3- Tiny & 3000 & $92.9 \%$ & $97.8 \%$ & $95.3 \%$ \\
& 1000 & $58.4 \%$ & $66.2 \%$ & $62,1 \%$ \\
& 2000 & $83.9 \%$ & $84.9 \%$ & $84,4 \%$ \\
& 3000 & $90.8 \%$ & $97.8 \%$ & $94,2 \%$ \\
\hline
\end{tabular}

Berdasarkan Tabel 2, YOLOv3 memiliki tingkat kebenaran yang lebih tinggi dari pada YOLOv3-Tiny. Sehingga YOLOv3 dapat menghasilkan nilai yang lebih baik. Nilai Precision, Recall, dan F1 Score terbaik yaitu pada step 3000 dengan nilai masing-masing 92.9\%, 97.8\%, dan 95.3\% pada algoritma YOLOv3. Pada penelitian yang telah dilakukan memiliki hasil yang cukup bagus sehingga sistem dapat diimplementasikan untuk deteksi korban bencana alam. Kesalahan deteksi pada sistem disebabkan karena objek yang terlalu kecil sehingga objek tidak tampak jelas seperti objek korban bencana. Selain itu, kesalahan deteksi juga dipengaruhi dari dataset yang kurang bervariatif.

\section{KESIMPULAN}

Pada penelitian ini, kami menyajikan algoritma YOLOv3 dan YOLOv3-Tiny untuk deteksi ada atau tidaknya korban bencana alam pada gambar. Dataset yang digunakan sebanyak 200 gambar dimana 100 gambar untuk data training dan 100 gambar untuk data testing. Training data dilakukan sampai pada step 3000. Berdasarkan eksperimen yang telah dilakukan telah diperoleh nilai F1 Score yang bagus yaitu sebesar $95.3 \%$ pada algoritma YOLOv3. Terdapat beberapa faktor yang mempengaruhi hasil deteksi, yaitu background objek pada gambar, posisi objek, dan tinggi / jarak objek. Untuk penelitian selanjutnya diharapkan dapat mengembangkan untuk menyelesaikan masalah tersebut supaya dapat mencapai hasil yang lebih efisien dalam membantu tim SAR dalam mengevakuasi korban bencana alam.

\section{DAFTAR PUSTAKA}

ADARSH, P., RATHI, P. \& KUMAR, M., 2020. YOLO v3-Tiny: Object Detection and Recognition using one stage improved model. Coimbatore, s.n.

ANGELO, K. M., 2018. A novel approach on object detection and tracking using adaptive background subtraction method. Chidambaram, India, s.n.

ARLINTA, D., 2019. Bencana Hidrometeorologi Paling Banyak, Sepanjang 2019 Terjadi 1.586 Bencana Alam. [Online] Available at: $<$ https://jogja.tribunnews.com/2019/04/30/b encana-hidrometeorologi-paling-banyaksepanjang-2019-terjadi-1586-bencanaalam?page $=$ all $>[$ Diakses 10 Maret 2020].
ASSHIDDIQIE, M. A. J., RAHMAT, B. \& ANGGRAENY, F. T., 2020. Deteksi Tanaman Tebu pada Lahan Pertanian Menggunakan Metode Convolutional Neural Network. Jurnal Informatika dan Sistem Informasi (JIFoSI), 1(1), pp. 229 237.

COROVIC, A., ILIĆ, V., ĐURIĆ, S. \& MALIŠA, 2018. The Real-Time Detection of Traffic Participants Using YOLO Algorithm. Serbia, s.n.

FANG, W., WANG, L. \& REN, P., 2020. TinierYOLO: A Real-Time Object DetectionMethod for Constrained Environments. IEEE Access, Volume 8, pp. 1935 - 1944.

HARTAWAN, D. R., PURBOYO, T. W. \& SETIANINGSIH， C., 2019. Disaster Victims Detection System Using Convolutional Neural Network (CNN) Method. Indonesia, s.n.

JIWOONG, C., DAYOUNG, C., HYUN, K. \& LEE, H.-J., 2019. Gaussian YOLOv3: An Accurate and Fast Object Detector Using Localization Uncertainty for Autonomous Driving. Seoul, IEEE International Conference on Computer Vision.

PRASETYO, N. A., PRANOWO \& SANTOSO, A. . J., 2020. Automatic Detection and Calculation of Palm Oil Fresh Fruit Bunches using Faster R-CNN. International Journal of Applied Science and Engineering, 17(2), pp. 121-134.

RAGHUNANDAN, A., MOHANA, RAGHAV, P. \& ARADHYA, H. V. R., 2018. Object Detection Algorithms for Video Surveillance Applications. Chennai, India, s.n.

RAMADHAN, M. I. \& PRIHANDOKO, 2017. Penerapan Data Mining untuk Analisis Data Bencana Milik BNBP Menggunakan Algoritma K-Means dan Linear Regression. Jurnal Informatika dan Komputer Volume 22, April, pp. 57-65.

RENTAO, Z. ET AL., 2019. Indoor Smoking Behavior Detection Based on YOLOv3-tiny. Hangzhou, 2019 Chinese Automation Congress (CAC).

SHARPE, S. M., SCHUMANN , A. W. \& BOYD, N. S., 2020. Goosegrass Detection in Strawberry and Tomato Using a Convolutional Neural Network. Scientific Reports, 10(9548), pp. 1 - 8.

YANG, Z. ET AL., 2019. Combining Yolov3-tiny Model with Dropblock for Tiny-face Detection. Xi'an, China, 2019 IEEE 19th International Conference on Communication Technology (ICCT).

ZENG, Z., GONG, Q. \& ZHANG, J., 2019. CNN Model Design of Gesture Recognition 
792 Jurnal Teknologi Informasi dan IImu Komputer (JTIIK), Vol. 8, No. 4, Agustus 2021, hlm. 787-792

Based on Tensorflow Framework. Xi'an, China, s.n.

ZHANG, Y., SHEN, Y. \& ZHANG, J., 2019. An improved tiny-yolov3 pedestrian detection algorithm. International Journal for Light and Electron Optics, Volume 183, pp. 1723. 